\title{
Liquid-Liquid Equilibrium of Methyl Esters of Fatty Acid / Methanol / Glycerol and Fatty Acid Ethyl Esters / Ethanol / Glycerol: A Case Study for Biodiesel Application
}

\author{
Ana Carolina de Sousa Maia, Iury Sousa e Silva, and Luiz Stragevitch
}

\begin{abstract}
Biodiesel is a fuel commonly produced through the process of transesterification or alcoholysis. In this reaction, triglycerides react with short chain alcohols, producing a mixture of fatty acid esters (biodiesel) and glycerol. Esters of fatty acids and glycerol are partially miscible, forming two liquid phases in the separation of these products. The determination of equilibrium data for liquid-liquid (ELL) for these systems is essential to a better understanding of the reaction process, improving the reaction rate, selectivity, and simulation and optimization of the reactor and the system of separation of products. In this paper we experimentally measured data for ELL pseudo-ternary systems of fatty acid methyl esters (FAME)/methanol/glycerol and fatty acid ethyl esters (FAEE)/ethanol/glycerol at 30, 45 and $60{ }^{\circ} \mathrm{C}$. The biodiesel used in this work was produced by transesterification of cottonseed oil. The measured experimental data were used to evaluate the prediction of the UNIFAC method for such systems.
\end{abstract}

Index Terms-Biodiesel, liquid-liquid equilibrium, UNIFAC.

\section{INTRODUCTION}

The production of biofuels derived from renewable sources is becoming an alternative to petroleum-based fuels due to high prices of fossil fuel, decreasing oil reserves and growing concerns about environmental issues [1].

In this context, biodiesel has become a potential alternative to reduce dependence on derivates from petroleum and decrease the emission of polluting gases such as $\mathrm{CO}_{2}, \mathrm{SOx}$ and particulates. Furthermore, biodiesel is renewable, biodegradable and nontoxic. It can be produced from a reaction known as transesterification in which triacylglycerols from vegetable oil or animal fat reacts with short-chain alcohols to form a mixture of glycerol and fatty acid esters (biodiesel).

Several sources of vegetable oil and animal fat can be used for biodiesel production. In the case of alcohol, are used short chain such as methanol and ethanol. Methanol is most commonly used alcohol to perform transesterification reaction due to lower cost and more favorable properties in the process. Since ethanol is an alcohol less toxic than the first and can be obtained from biomass, providing a biodiesel which production is completely renewable [2], [3].

Because of the reaction be reversible, the alcohol is used in

Manscript reveived July 1, 2013; revised September 5, 2013

The authors are with the Fuels Laboratory, Department of Chemical Engineering, Federal University of Pernambuco, Av Professor Arthur de Sá S/N, Cidade Universitária, 5070-521, Recife-PE, Brazil (e-mail: iury.silva@ufpe.br). excess. High conversions of esters are reported in the literature for a molar ratio alcohol/oil 6:1 [4]. Catalysts are generally added to the system to accelerate the reaction.

The fatty acid esters and glycerol, obtained in the transesterification reaction are partially miscible, so that during the separation of these products, there is the formation of two liquid phases [5]. The denser phase is rich in glycerol and the less dense phase contains the fatty acid esters which will be used as biodiesel after the purification steps. The unreacted alcohol is distributed between two liquid phases [2].

Knowledge of phase equilibria of these systems is necessary for a better understanding of the process and optimization of the reactor and separation systems [1]. Thus, the adequate description of the distribution of the products of transesterification between the two phases, in a wide range of process conditions, is essential for the study and design of the equipment involved in the production and purification of biodiesel [6]. Furthermore, simulations for the development of new processes for such systems require thermodynamic models that can adequately describe these mixtures [5].

The thermodynamic modeling of phase liquid-liquid equilibrium requires that be determined, among the existing thermodynamic models, the most suitable to represent the excess Gibbs energy (GE). In this sense, the method UNIFAC (Universal Quasi-Chemical Functional Group Activity Coefficient) uses existing experimental data to predict the phase equilibrium of systems for which experimental data are not available. The UNIFAC is a group contribution method in which a liquid mixture can be considered a solution of structural units from which the molecules are formed [7].

In this work were determined the of liquid-liquid equilibrium (LLE) for the pseudo-ternary systems of fatty acid methyl ester (FAME)/methanol/glycerol and fatty acid ethyl ester (FAEE)/ethanol/glycerol at 30,45 and $60^{\circ} \mathrm{C}$. The measured data were used for evaluation of the performance of models UNIFAC and UNIFAC-Dortmund to prediction the LLE of this type of system.

\section{Methodology}

\section{A. Materials and Methods}

To determine the LLE data were used glycerol $(99.5 \%$ VETEC), methanol ( $\geq 99.9 \%$, Merck), ethanol $(\geq 99.9 \%$, Merck) and methyl and ethyl biodiesel produced in two 
different ways. For the pseudo-ternary system FAME/methanol/glycerol was used a biodiesel of industrial origin, produced by methanolysis of cottonseed oil. For the pseudo-ternary system FAEE / ethanol / glycerol, ethyl biodiesel cotton was produced by ethanolysis of refined cottonseed oil with the following reaction conditions: molar ratio alcohol/oil 6/1; catalyst $\mathrm{NaOH}(\geq 99.0 \%$, Merck), mass fraction of catalyst in relation to the mass of oil $0.75 \%$, stirring $300 \mathrm{rpm}$ and reaction temperature $50{ }^{\circ} \mathrm{C}$. The ester content in the methyl biodiesel was $99.1 \%$ and in the ethyl biodiesel $97.2 \%$, determined by gas chromatography according to EN 14103.

The composition of each phase was performed by gas chromatography with flame ionization detector using a capillary column chromatography DB-1 ( $\&$ W) with a length of $30 \mathrm{~m}$, internal diameter $0.32 \mathrm{~mm}$ and thickness of film of 0.3 micrometers. Hydrogen $(99.999 \%)$ was used as carrier gas and isopropanol ( $\geq 99.8 \%$, Merck) was used as solvent for homogenization of samples.

\section{B. Experimental Procedure}

Glass cells with a volume of $100 \mathrm{~mL}$ and mechanical stirrers were used to perform LLE measures at atmospheric pressure. The ternary mixtures ester/alcohol/glycerol were prepared gravimetrically and the three components of the mixture were added directly to the LLE cell. To maintain cells at constant temperature, was used a thermostatic bath (Julabo TE-184) using water as the heating fluid. The system was maintained at the desired temperature with an accuracy of $\pm 0.2{ }^{\circ} \mathrm{C}$. To measure the temperature of the mixture in the cell was used a calibrated temperature sensor PT100.

To promote contact between the phases, the system was kept under vigorous stirring by mechanical stirrer for one hour and then the system was allowed to stand to reach equilibrium after the phase separation. After equilibrium attained, aliquots of each phase were collected with a glass syringe and the mass fraction of each determined by gas chromatography.

\section{Thermodynamic Modeling}

The prediction of LLE for the systems experimentally evaluated was performed using a liquid-liquid flash calculation (LLF) isotherm at 30, 45 and $60^{\circ} \mathrm{C}$ and the activity coefficients were predicted by group contribution methods UNIFAC and UNIFAC-Dortmund. The comparison between experimental and calculated values by UNIFAC was performed using the average deviation given by

$$
\Delta w=100 \sqrt{\frac{\sum_{j=1}^{N_{\mathrm{P}}} \sum_{i=1}^{N_{\mathrm{C}}}\left[\left(w_{i j}^{\mathrm{I}, \mathrm{I} e x p}-w_{i j}^{\mathrm{I}, \mathrm{cal}}\right)^{2}+\left(w_{i j}^{\mathrm{II}, \mathrm{exp}}-w_{i j}^{\mathrm{II}, \mathrm{cal}}\right)^{2}\right]}{2 N_{\mathrm{C}} N_{\mathrm{P}}}}
$$

where $w_{i j}$ is the mass fraction of component $\mathrm{i}$ in the point $\mathrm{j}$, I and II are the phases in equilibrium, exp and cal denote measured and calculated values, respectively, $\mathrm{NC}$ is the number of components and NP is the number of experimental points.

\section{RESULTS AND DISCUSSION}

The experimental data of LLE for the systems methyl esters/methanol/glycerol and ethyl esters/ethanol/glycerol at 30,45 and $60^{\circ} \mathrm{C}$ are shown in Tables 1 and 2, respectively.

The results show, as expected, that the glycerol phase is richer in alcohol (methanol or ethanol) than the ester phase. For the ethyl systems, the results show that although ethanol found in greater quantity in the glycerol rich phase, the presence of this component in the ester rich phase is greater than that observed for methanol. In the case of ethyl systems, the presence of ethanol in this system also contributes to the presence of higher amount of glycerol in the ester rich phase since this alcohol promotes a greater dispersion of glycerin in the biodiesel.

For both systems studied, the increase in temperature promotes increased miscibility of the components and the phase rich in ester has a higher amount of alcohol. The experimental data were evaluated by Othmer and Tobias correlation [8] as shown in Fig. 1.
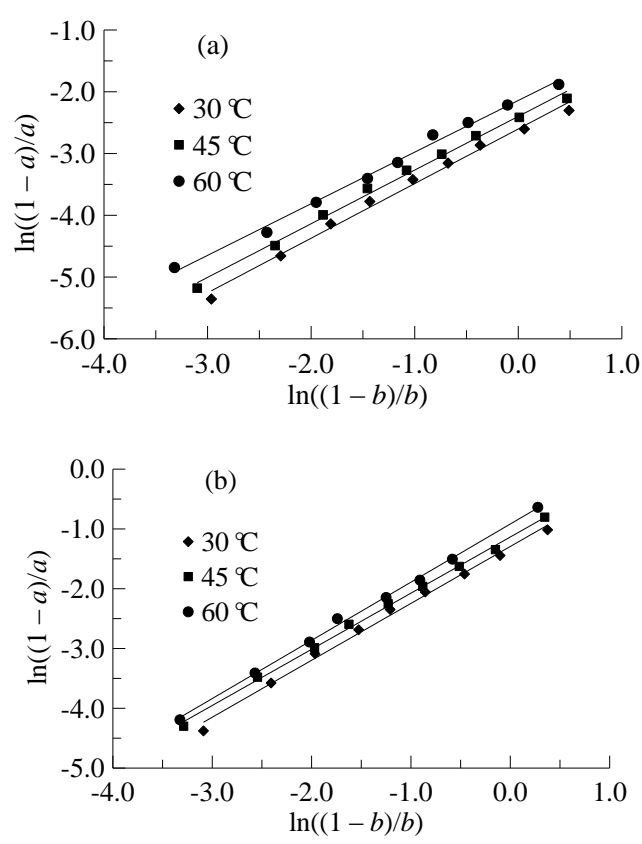

Fig. 1. Othmer-Tobias plot for (a) FAME / methanol / glycerol and (b) FAEE / ethanol / glycerol. a is the fraction of ester in the ester rich phase and b is the fraction of glycerol in glycerol rich phase.

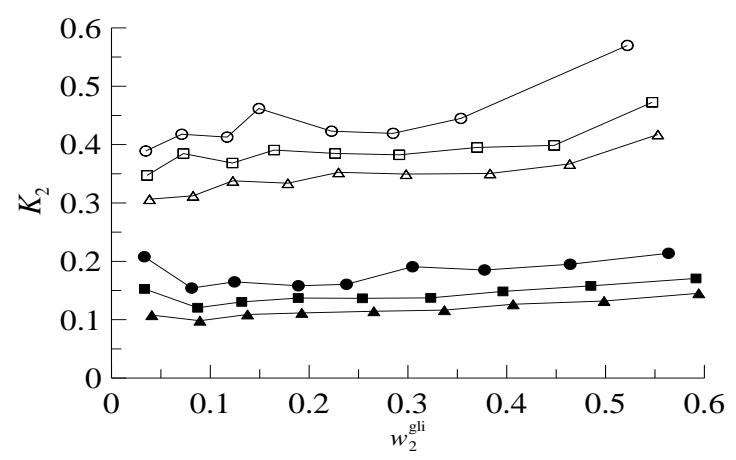

Fig. 2. Distribution coefficient of methanol: $30^{\circ} \mathrm{C}(\boldsymbol{\Delta}), 45^{\circ} \mathrm{C}(\boldsymbol{\bullet}) 60^{\circ} \mathrm{C}(\bullet)$ and ethanol: $30^{\circ} \mathrm{C}(\Delta), 45^{\circ} \mathrm{C}(\square)$ e $60^{\circ} \mathrm{C}(\circ)$.

The distribution of alcohol between the ester and glycerin phases can be analyzed through the coefficient of distribution given by $\mathrm{K} 2$ :

where is the fraction of alcohol in the ester phase and is the fraction of alcohol in glycerol phase. Fig. 2 shows behavior 
of the distribution coefficient of methanol and ethanol.

As can be seen in Fig. 2, the coefficient of distribution of ethanol is smaller than 1, indicating higher concentration of alcohol in glycerol phase than in the ester phase. The effect is expected since methanol, ethanol and glycerol have similar structures with $\mathrm{O}-\mathrm{H}$ groups. The attractive interaction of these molecules is by hydrogen bonding which means that alcohol will be distributed preferentially in the glycerol phase.

The experimental results show that the distribution coefficient of alcohol increases with increasing temperature in both systems. This result is also expected since the association effects will decrease with temperature (Andreatta et al., 2008).

\section{LIQUID-LIQUID EQUILIBRIUM PREDICTION}

Biodiesel is composed of a mixture of fatty acid esters of different chains, but the system can be approximated as a pseudo ternary system (Zhou et al., 2006, Cheng et al., 2009). The biodiesel can then be considered as consisting of a single ester (ester representative), which best represents the biodiesel used.

In this work, the methyl biodiesel was represented by methyl linoleate, and the ethyl biodiesel was represented by ethyl linoleate because these esters represent over $50 \%$ of the composition of the biodiesel. The methyl biodiesel presented $57.9 \%$ of methyl linoleate and the ethyl biodiesel $53.8 \%$ of ethyl linoleate.

TABLE I: DISTRIBUTION OF GROUPS FOR UNIFAC AND UNIFAC-DORTMUND

\begin{tabular}{ccccc}
\multicolumn{5}{c}{ METHODS $\left(\mathrm{CH}_{3}, \mathrm{CH}_{2}, \mathrm{CH}, \mathrm{CH}=\mathrm{CH}\right)$} \\
\hline Component & $\mathrm{CH}_{3}$ & $\mathrm{CH}_{2}$ & $\mathrm{CH}$ & $\mathrm{CH}=\mathrm{CH}$ \\
\hline Methyl Linoleate $^{a, b}$ & 2 & 11 & 0 & 2 \\
Ethyl Linoleate $^{a, b}$ & 2 & 12 & 0 & 2 \\
Methanol $^{a}$ & 1 & 0 & 0 & 0 \\
Methanol $^{b}$ & 0 & 0 & 0 & 0 \\
Ethanol $^{a, b}$ & 1 & 1 & 0 & 0 \\
Glycerol $^{a}$ & 0 & 2 & 1 & 0 \\
Glycerol $^{b}$ & 0 & 2 & 1 & 0 \\
\hline
\end{tabular}

${ }^{a}$ UNIFAC; ${ }^{b}$ UNIFAC-Dortmund;

TABLE II: DISTRIBUTION OF GROUPS FOR UNIFAC AND UNIFAC-DORTMUND $\operatorname{MeTHODS}\left(\mathrm{OH} / \mathrm{OH}_{-\mathrm{p}}, \mathrm{OH}_{-\mathrm{s}}, \mathrm{CH}_{2} \mathrm{COO}, \mathrm{CH}_{3} \mathrm{OH}\right)$

\begin{tabular}{ccccc}
\hline Component & $\mathrm{OH} / \mathrm{OH}_{-\mathrm{p}}$ & $\mathrm{OH}_{-\mathrm{s}}$ & $\mathrm{CH}_{2} \mathrm{COO}$ & $\mathrm{CH}_{3} \mathrm{OH}$ \\
\hline Methyl Linoleate $^{a, b}$ & 2 & 11 & 0 & 2 \\
Ethyl Linoleate $^{a, b}$ & 2 & 12 & 0 & 2 \\
Methanol $^{a}$ & 1 & 0 & 0 & 0 \\
Methanol $^{b}$ & 0 & 0 & 0 & 0 \\
Ethanol $^{a, b}$ & 1 & 1 & 0 & 0 \\
Glycerol $^{a}$ & 0 & 2 & 1 & 0 \\
Glycerol $^{b}$ & 0 & 2 & 1 & 0 \\
\hline
\end{tabular}

${ }^{a}$ UNIFAC; ${ }^{b}$ UNIFAC-Dortmund

Table I and Table II shows the distribution of groups of system components for the UNIFAC and UNIFAC-Dortmund methods. Figs. 3-8 show a comparison between experimental data and predictions by the UNIFAC and UNIFAC-Dortmund methods for the systems methyl esters/methanol/glycerol and ethyl esters/ethanol/glycerol with different equilibrium temperatures $\left(30,45\right.$ and $\left.60^{\circ} \mathrm{C}\right)$.

Figs. 3-5 show the experimental data for liquid-liquid equilibrium of methyl esther/methanol/glycerol with different temperatures, 30, 45 and $60^{\circ} \mathrm{C}$, and the thermodynamic modeling with UNIFAC and UNIFAC Dortmund models.

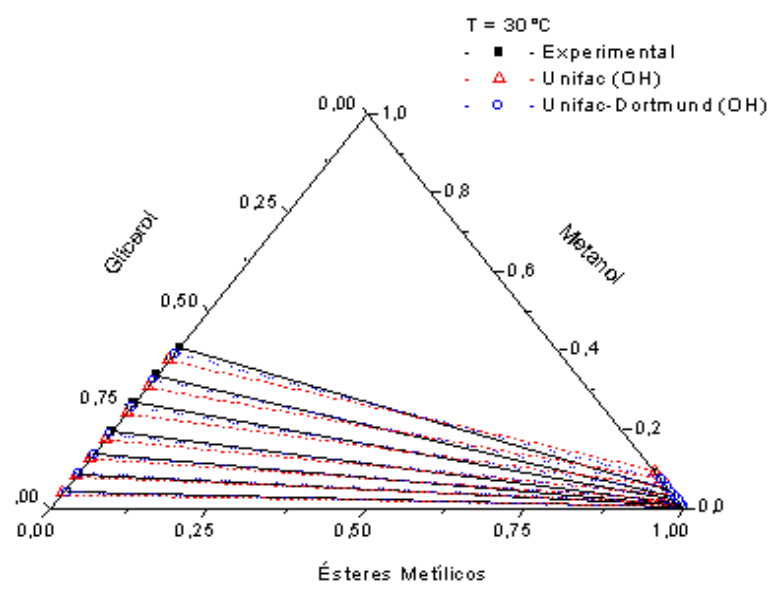

Fig. 3. Liquid-liquid equilibrium diagram system of methyl ester/methanol/glycerol at $30^{\circ} \mathrm{C}$

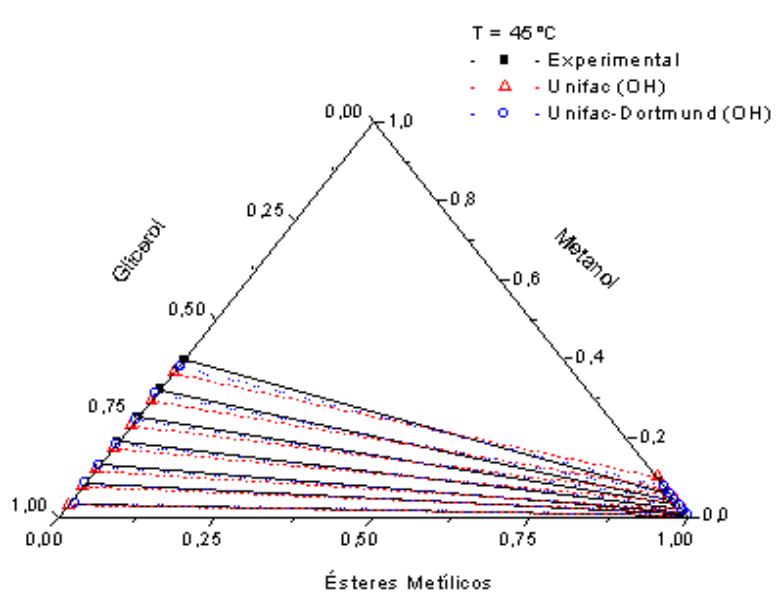

Fig. 4. Liquid-liquid equilibrium diagram system of methyl ester/methanol/glycerol at $45^{\circ} \mathrm{C}$

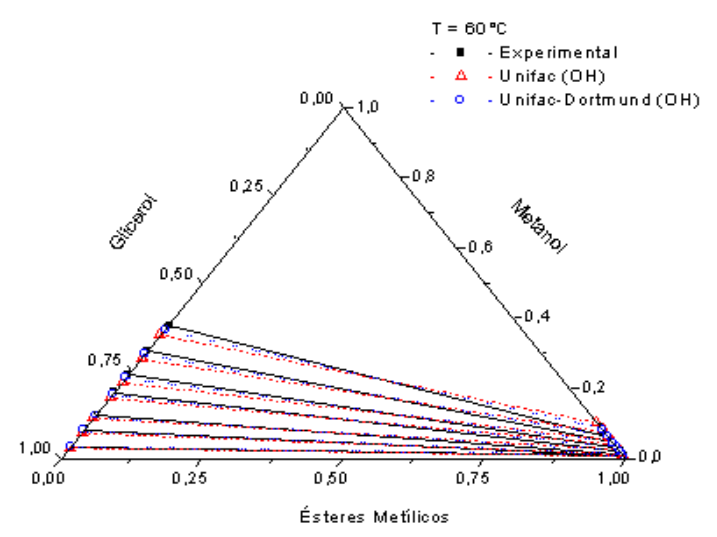

Fig. 5. Liquid-liquid equilibrium diagram system of methyl ester/methanol/glycerol at $60^{\circ} \mathrm{C}$

Figs. 6-8 show the experimental data for liquid-liquid equilibrium of ethyl esther/ethanol/glycerol with different temperatures, 30,45 and $60^{\circ} \mathrm{C}$, and the thermodynamic modeling with UNIFAC and UNIFAC Dortmund models. 


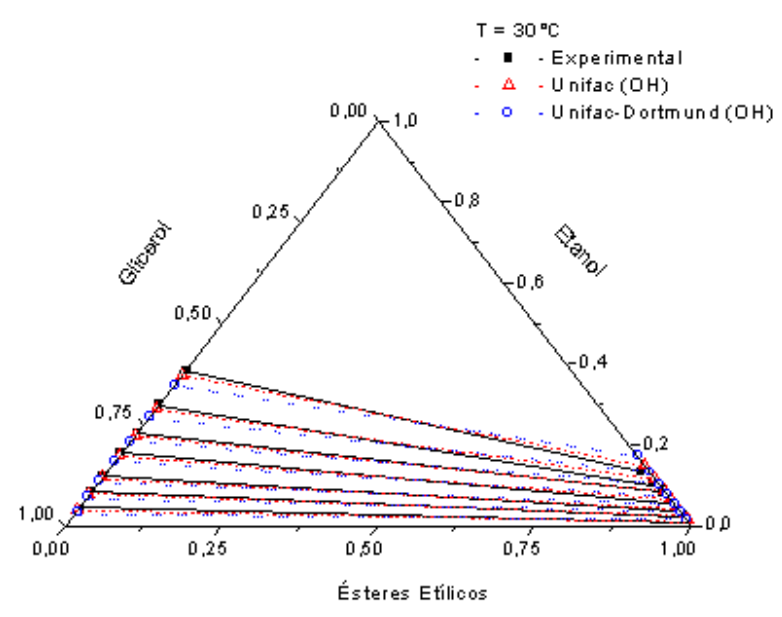

Fig. 6. Liquid-liquid equilibrium diagram system of ethyl ester/ethanol/glycerol at $30^{\circ} \mathrm{C}$

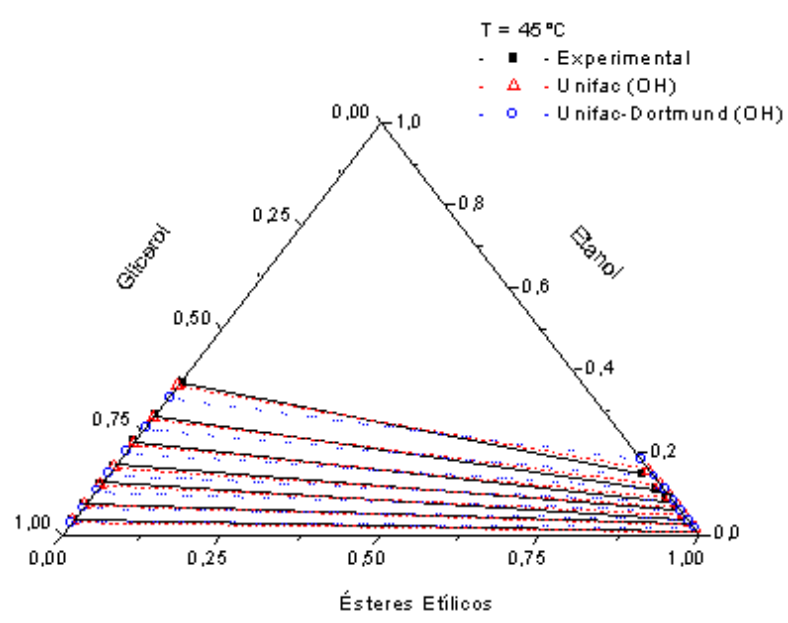

Fig.7. Liquid-liquid equilibrium diagram system of ethyl ester/ethanol/glycerol at $45^{\circ} \mathrm{C}$

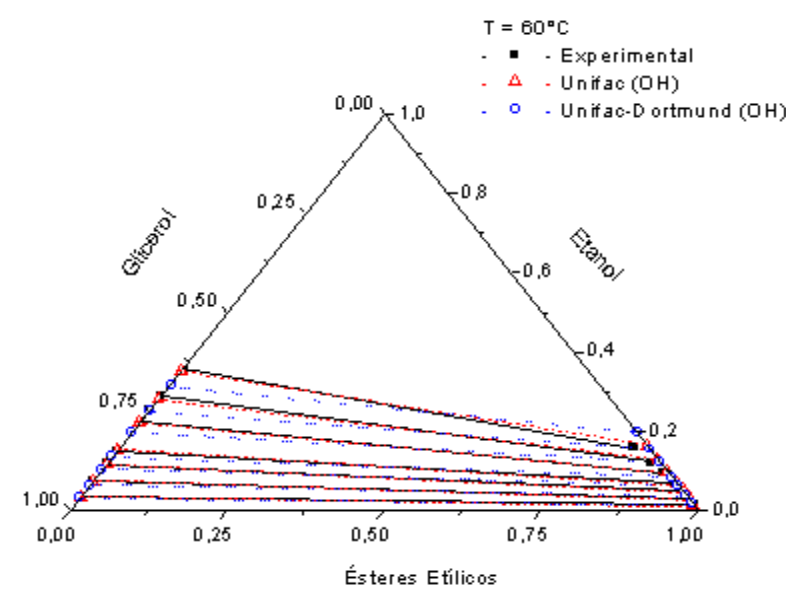

Fig. 8. Liquid-liquid equilibrium diagram system of ethyl ester/ethanol/glycerol at $60^{\circ} \mathrm{C}$

As can be seen in Figs. 3-8, the values predicted by the models UNIFAC and UNIFAC-Dortmund represent qualitatively the systems with larger deviations with increasing concentration of alcohol in the system. According to Oliveira et al. (2011), the presence of a polar compound with strong associative interactions increases the complexity of the system making difficult the use of conventional thermodynamic models.

Table III and Table IV presents the average deviations between the calculated and experimental compositions. The analysis of Table III and Table IV shows that the prediction of UNIFAC-Dortmund method is better than the prediction of UNIFAC method for the methyl ester systems while the reverse is observed for the ethyl systems.

TABLE III: AVERAGE DEVIATIONS OF LLE WITH UNIFAC AND UNIFAC-DORTMUND PREDICTION METHOD WITH METHYL ESTER SYSTEM

\begin{tabular}{ccc}
\hline \multicolumn{3}{c}{$\Delta \mathrm{w} / \%$} \\
\hline \multicolumn{3}{c}{ Methy ester system } \\
\hline Temperature & UNIFAC & UNIFAC-Dortmund \\
\hline $30^{\circ} \mathrm{C}$ & 1,93 & 30 \\
$45^{\circ} \mathrm{C}$ & 1,80 & 45 \\
$60^{\circ} \mathrm{C}$ & 1,44 & 60 \\
\hline
\end{tabular}

TABLE IV: AVERAGE DEVIATIONS OF LLE WITH UNIFAC AND UNIFAC-DORTMUND PREDICTION METHOD WITH METHYL ESTER SYSTEM

\begin{tabular}{ccc}
\hline \multicolumn{3}{c}{$\Delta \mathrm{w} / \%$} \\
\hline \multicolumn{3}{c}{ Ethy ester system } \\
\hline Temperature & UNIFAC & UNIFAC-Dortmund \\
\hline $30^{\circ} \mathrm{C}$ & 0,54 & 1,74 \\
$45^{\circ} \mathrm{C}$ & 0,52 & 1,82 \\
$60^{\circ} \mathrm{C}$ & 0,68 & 1,87 \\
\hline
\end{tabular}

\section{CONCLUSION}

LLE data for systems FAME/methanol/glycerol and FAEE/ethanol/glycerol were measured at temperatures of 30 , 45 and $60^{\circ} \mathrm{C}$. The results showed that alcohol is distributed preferentially in the glycerol phase and ethanol concentration is higher than methanol in the respective ester systems. For co-solvency effect of ethanol, a greater amount of glycerol was observed in the ester-rich phase. The experimental data were analyzed by the Othmer-Tobias correlation having obtained satisfactory linearity. The set of currently available UNIFAC parameters was evaluated based on experimental data measured, considering pseudo ternary systems using the methyl and ethyl linoleate as pseudo components representative. The results of the predictions of methods UNIFAC and UNIFAC-Dortmund were considered qualitative.

\section{NOTATIONS}

LLE: Liquid-Liquid Equilibrium

UNIFAC: UNIQUAC Functional-Group Activity Coefficients

$\Delta \mathrm{W}$ : Average deviation

$K_{2}$ : Coefficient of distribution

\section{ACKNOWLEDGMENT}

The authors thank FINEP for financial support and CETENE, providing samples of methyl biodiesel. CAPES and PRH 28/ PETROBRÁS for providing a master scholarship.

\section{REFERENCES}

[1] A. E. Andreatta, L. M. Casás, P. Hegel, S. B. Bottini, and E. A Brignole, "Phase equilibria in ternary mixtures of methyl oleate, glycerol, and methanol," Ind. Eng. Chem. Res, vol. 47, pp. 5157-5164, 2008.

[2] M. B. Oliveira, S. Barbedo, J. I. Soletti, S. H. V. Carvalho, A. J. Queimada, and J. A. P. Coutinho, "Liquid-liquid equilibria for the canola oil biodiesel + ethanol + glycerol system," Fuel, pp. 2738-274, 2011. 
[3] A. B. Machado, Y. C. Ardila, L. H. Oliveira, M. Aznar, and M. R. W. Maciel, "Liquid_Liquid Equilibrium Study in Ternary Castor Oil Biodiesel + Ethanol + Glycerol and Quaternary Castor Oil Biodiesel + Ethanol + Glycerol + NaOH Systems at (298.2 and 333.2) K.," J. Chem. Eng. Data., vol. 56, pp. 2196-2201, 2011.

[4] U. Rashid, F. Anwar, and G. Knothe, "Evaluation of biodiesel obtained from cottonseed oil," Fuel Proc. Tech, vol. 90, pp. 1157-1163, 2009

[5] D. S. Negi, F. Sobotka, T. Kimmel, G. Wonzny, and R. Schomcker, "Liquid-liquid phase equilibrium in glycerol-methanol-methyl oleate and glycerol-monoolein-methyl oleate ternary systems," Ind. Eng. Chem. Res., vol. 45, pp. 3693-3696, 2006.

[6] A. B. Machado, Y. C. Ardila, L. H. Oliveira, M. Aznar, and M. R. W Maciel, "Liquid_liquid equilibrium study in ternary castor oil biodiesel + ethanol + glycerol and quaternary castor oil biodiesel + ethanol + glycerol $+\mathrm{NaOH}$ systems at (298.2 and 333.2) K.," J. Chem. Eng. Data., vol. 56, pp. 2196-2201, 2011.
[7] J. M. Prausnitz, B. E. Poling, and J. P. O'Connell, The Properties of Gases and Liquids, McGraw-Hill Book Company, New York, 2001.

[8] D. T. Othmer and P. E. Tobias, "Tie line correlation," Ind. Eng. Chem., vol. 34, pp. 693-69, 1942.

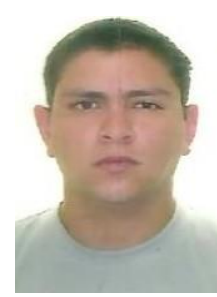

Iury Sousa e Silva was born on July 15, 1988. He got his bachelor's degree in Chemical Engineering from Federak University od Pernambuco (UFPE), between 2006 to 2010. Process Engineer between 2010 to 2012 at M\&G Fibers. Major Field of study is thermodynamics and phase equilibrium. Master in Chemical Engineering program sponsored by PRH28/Petrobrás. 